\begin{abstract}
"Mircea cel Batran" Naval Academy Scientific Bulletin, Volume XX - 2017 - Issue 2
The journal is indexed in: PROQUEST / DOAJ / Crossref / EBSCOhost/ INDEX COPERNICUS/ OAJI / DRJI I JOURNAL INDEX / I2OR / SCIENCE LIBRARY INDEX / Google Scholar / Academic Keys / ROAD Open Access I Academic Resources / Scientific Indexing Services / SCIPIOI JIFACTOR
\end{abstract}

\title{
PRINCIPLES OF TRAINING IN LINE WITH THE NEW THINKING AND ACTION
}

\author{
Yuliya DONCHEVA ${ }^{1}$ \\ ${ }^{1}$ Assoc. prof. PhD Faculty of Natural Sciences and Education, Department of Pedagogy, Psychology and \\ History, "Angel Kanchev" University of Ruse, Bulgaria, E-mail: jdoncheva@uni-ruse.bg
}

\begin{abstract}
Education of the Industrial Age, which gave knowledge needed to become a good worker in a specific occupation, turning students into standard products conveying educational production. Now learning through interaction atmosphere born of ingenuity and spontaneity that promote intuition and improvisation as valuable expressions of individuality and creativity. To construct successful learning strategies, it is necessary to know the context of social development. Scrutinizing social processes is more urgent today precisely in time and change the paradigm industrial age inherited from the information. The revolution that was born of the merger of computerization, means of communication and the media is the most powerful force shaping the world today. The new moments are manifested as the ability of man and his "smart innings," such as computer and communication technologies. The object of this publication are the characteristics of postmodern thinking, knowledge and behaviors that should guide when inventing models of education now, at the beginning of the XXI century.
\end{abstract}

Key words: Principles, thinking, behavior, training, computer and communication technologies

To construct successful learning strategies, it is necessary to know the context of social development. Scrutinizing social processes is extremely urgent today precisely in time and change the paradigm industrial age inherited from the information. The revolution that was born of the merger of computerization, means of communication and the media is the most powerful force shaping the world today. [Celente, p. 17-18] huge potential created by our tools of the new reality we create thanks to them, put before us require that you use their endless possibilities as they master to perfection. But while changing environment through its technical achievements, intensive interaction with it changes

us.

The new moments are manifested as the ability of man and his "smart innings," such as computer and communication technologies. The object of this brief work are the characteristics of postmodern thinking, knowledge and behaviors that should guide when inventing models of education now, at the beginning of the $\mathrm{XXI}$ century.

The change in us. The interaction with the computer affects this intelligence body, consciousness itself, altering the fundamental processes - thinking, learning, and learning. It is primarily a tool to help produce and communicate. The way we write, we are creating is a method of continuous experimentation in intensive dialogue. Using the computer as a tool and medium replaced traditional ideas of making text or reading. Mental field is advanced and dynamic, because today's writing is constantly editing in windows offering simultaneous access to diverse material. The feeling of close interaction with the machine is enhanced by individual way she can embody our ideas and express our way to solutions. Time and space do not have a starring role as before, because through multiple windows on the screen almost simultaneously are a few places or communicate with different people, switching quickly and often. As a result, the identity is presented as "amount of distributed presence." [Turkle, p. 13]

Through technology we learn to live in virtual worlds by developing new social and cultural sensitivity. We create not only text, but also themselves, constructing new selves through social interaction. This leads to fundamental changes in the way we create and experience human identity. Pluralism of views in the postmodern era provides us with a philosophical basis and technological base to immersion in different not experienced aspects of the self, atypical social roles to another person, other races in the opposite sex.

The main functions that perceive of computer technology in the way they work and attitude towards the world are simulation, navigation and interaction. Culture of calculation, which was clear, logical, hierarchical structures had shifted from a culture of simulation in which knowledge is acquired through experience - actions in real or virtual reality. What controls the process of acquiring experience are not instructions, but only the limitations of the system - rules of medium technical capabilities. While life on screen is an illusion if you see work for you, it has all reality it needs. [Turkle, p. 24] Once through this fictional environments, acquire skills (often inaccessible in real terms), learn, communicate and interact, we can even make it to creation, therefore it is functionally significant for us.

Principles of training in line with the new thinking and action. 


\section{"Mircea cel Batran" Naval Academy Scientific Bulletin, Volume XX - 2017 - Issue 2 \\ The journal is indexed in: PROQUEST / DOAJ / Crossref / EBSCOhost/ INDEX COPERNICUS/ OAJI / DRJI I JOURNAL INDEX / I2OR / SCIENCE LIBRARY INDEX / Google Scholar / Academic Keys / ROAD Open Access I Academic Resources / Scientific Indexing Services / SCIPIOI JIFACTOR}

Learning by doing. To play and experience is the main driver. While there is no awareness that study or work, you do it while having fun. Learning system, playing with its capabilities. Design their own projects picking sources, ways and means, in a new way structured information. Differentiated parts by criteria and collected in a unique network of links, jigsaw born essence, all every time and for every person differently. You choose, you find your way and defend independent thinking in the fight against postulated truths. The result is a patchwork of independent solutions to specific tasks achieved by individual way.

Indivisibility of production and communication. By acting subject, object and tools are combined into a single whole, which includes the object-oriented productive aspect and oriented human communicative aspect. [RossiLandi 1983, Cole, p. 174] In human behavior, technological, economic and social conditions create and constantly expand and complicate activities which require verbal communication. In different situations the efforts of all involved to coordinate new and diverse ways. Recognizing type requires communication skills on the various formats of expression and competence in terms of situational background and context of the overall discourse.

Functionality. When the motivation for an activity arises by itself, it makes the learner focused and resourceful. Cole notes that the practice appears both environment and result precondition for human thinking. [Cole, p. 172]. It presents knowledge in the hierarchy of relationships and values. It provides cultural patterns which leaves the knowledge of the individual and which empties his work. Thus socio-cultural plan sets the basis of each activity, remaining open for its development and retaliatory result.

Interactivity. The family is not ubiquitous unit of society. Today important for us are the groups in which we choose to participate - groups of independent individuals who share similar interests, values, lifestyle and responsibilities to each other and to the public. Studies of Labov [Labov, p. 205-206] have shown that verbal behavior of the most important is the social situation. When children are involved to work together with each other and with adults, they learn to build myself as a turning nature into culture. Joint mediated activity of people manifested their sense presents objects such as conflicts of ideas, turning them from the collective team. Thus was born the collective sense. Education of the Industrial Age, which provides the knowledge necessary to become a good worker in a specific occupation, turning students into standard products conveying educational production. Now learning through interaction atmosphere born of ingenuity and spontaneity that promote intuition and improvisation as valuable expressions of individuality and creativity [Tsankova].

Visual culture. The civilized person experiences matter and through its abstract images. He realizes the self in alternating series of real and virtual worlds. Postmodern era requires synthetic solutions that act as a whole and immediately, relies on images. They are a universal language and more intuitive perception. In a state of physical relaxation and concentration on the visual image, mental picture of the object and the bundle of thoughts fixed it directly transmitted to the subconscious. [Ivanov, p. 237]

Syncretism. Knowledge should not be strictly differentiated but to catch links and to preserve the overall monolithic perception, which is natural to the way things exist. This is the lesson of the East, addressed to final analytical construction and rationalism of the West. Going into objects, not to divide them and distanced them realize only intellectually. To feel the essence and moral force of all life should be immersion, to identify with him. [Petrova]

Multiculturalism. Condition for knowledge and behavior in modern times to meet with the values, norms and social practices set by the socio-cultural framework of the various communities. [Doncheva, p. 293] enrichment interpretation of various models facilitates positioning us in the cultural environment of the new global society. Integrating learning with everyday life and art with science in cognitive approaches [Janakiev], combines the intellectual with the emotional, spiritual and physical aspect of personal growth and connects it with public realization.

Cosmic consciousness. Youth today brings a new responsibility for the world - to realize the unity in diversity of Matter, Energy and Mind (information) and to perceive life as a stream of constant change and movement. "Everything in the universe is alive because it contains matter and energy, and they are always accompanied by manifestations of consciousness and life." Therefore man is responsible for everything that occurs within the limits of its influence. The word is a center of ideas, and the idea - the center of the mental image. "To accent strength of the idea and ability to embody in action, we must fix in your mind clear conception of the meaning of each word." [Ivanov, p. 167-197].

Forms of language training meeting postmodern principles. According to $\mathrm{F}$. K. Bartlet there are closed systems of learning that have a fixed purpose and structure, the elements and acceptable answers are known. In an open system the learner is a researcher, not a 


\section{"Mircea cel Batran" Naval Academy Scientific Bulletin, Volume XX - 2017 - Issue 2 \\ The journal is indexed in: PROQUEST / DOAJ / Crossref / EBSCOhost/ INDEX COPERNICUS/ OAJI / DRJI I JOURNAL INDEX / I2OR / SCIENCE LIBRARY INDEX / Google Scholar / Academic Keys / ROAD Open Access I Academic Resources / Scientific Indexing Services / SCIPIOI JIFACTOR}

spectator. There are objective and not asking approaches and limitations. "In an open system specification answer is a new step in the broader area of interest." [Bartlet and Cole, p. 291] It is not the particular knowledge and the path to it. It is essential to form a desire to explore the world and its possibilities. To experiment with thinking and behavior in the field of their own individuality becomes not parching source of motivating force for the development of personality.

Role training is not a new teaching method, but in line with the highest degree of way is willing to learn playing today's young man. In order to form an environment not starting from individual visual or verbal stimuli, and creates a situation synthetic fixed by theme and genre of communication, e.g., "The Quebec Bridge" "trial". So the set framework can cover all sorts of types of speech activity - reading and writing (in preliminary work with the materials) later listening, speaking, taking notes. In practice, the focus is not on individual characters (roles), and on the development of the simulated situation, i.e. implementation of simulation games.

Make a step towards purely communicative tasks that unfold learned in the free form of the living word. Now the task "to make a speech" is reflected in the more open forms of self-expression that provide a variety of types of discourses as reporting, commentary, discussion, proving the thesis and others. To do this requires a wide range of shapes, different themed social content, tone and opportunities for written and oral communication: workshops ateliers, workshops, eg., For discussion, editing and producing "edition"; projects with different focus - social, cultural, artistic; various genres of communication that provide opportunities to combine types of text - interview, studio debate scenario and others. [Sharlanova]

Initially focusing on situational training, which preserves the socio-psychological characteristics of the participants - public speech a "rhetoric" and a "forum". What is tested in training is: a description of the architectural object of design, technological and consumer point of view; presentation, discussion, approval or rejection of the project; "Brainstorming" to solve the problem - as ways to develop the site in a different discourse.

At the next stage experimental tasks where learners take social roles defined by simulation games "protection project", "judgment", "advertising promotion of the product," "press conference." Carefully plan the appropriate communication strategies and materials made for individual countries in staging speech situation. The integral nature of learning requires endorsement by all who work in hours, without underestimating the individual approach to the elements and actors, or affecting balance and gradation. [Vitanova]

Completely impossible to tests to note personal progress in communicative competence, so for the specific purpose developed specific tools to control skills on which he worked. These are only reports and discuss expectations, reactions and satisfaction of simulation. A very important task was assigned to the active audience, which had the role of "jury", "advertising target groups", "audience" and so on. In the prerogatives and broadcasting expert critics to ask questions and more. The reaction to it is an important gauge of the criteria for adequacy of the speeches and the degree of their persuasiveness. Mid simplicity supports the efforts of each student and boost his confidence and activity.

\section{Lessons learned are:}

- The arrangement of the circumstances in which action is carried out can approach behavior in the classroom to model every day. The language is an integral part of the overall process of assimilation of culture. The model of "simulated everyday" captures the real elements of the open system should be modeled. Combines interest, attention and imagination of the participants. Speech action activates the learner to invest in speech thought, will and emotional strength and influence on the environment, knowing that it was not his choice.

- Learning through simulation game creates a suitable environment leading to the development experiences. Is performed symbolic mediation whose highest expression is the language as a means of controlling behavior. Simulated position gives ideas and scope of interpretation as individual speech provoked reaction socially structured linguistic environment.

- If the goal includes concentration on the role develops observation to speech and nonverbal behavior of different social groups in all sorts of psychological conditions. A chance to master the stylistic registers and rely sociolinguistic markers, which is a remarkable success for the students. In developing the language field marker is seen as a means of political advertising and other speech-based strategies that transfer bridges between different qualifications and skills of the participants. Response interaction is essential to success.

\section{Difficulties and hazards:}

- When simulating synthetic situation is more difficult to identify individual cognitive tasks than when given in increments instruction. Can easily be ignored moments like classification, summary conclusions that are not differentiated in the flow of training, mimic natural situations. The teacher, but to determine the field in which to work learners often need to structure activities so as not to hurt performance due to poor language or 
"Mircea cel Batran" Naval Academy Scientific Bulletin, Volume XX - 2017 - Issue 2

The journal is indexed in: PROQUEST / DOAJ / Crossref / EBSCOhost/ INDEX COPERNICUS/ OAJI / DRJI I JOURNAL INDEX / I2OR / SCIENCE LIBRARY INDEX / Google Scholar / Academic Keys / ROAD Open Access I Academic Resources / Scientific Indexing Services / SCIPIOI JIFACTOR

experience. It is necessary at all times to maintain access to the information and instructions. Of course, in the new century learning will increasingly evolve towards the use of simulated possibilities of virtual reality and computermediated communication. Advances in distance education is possible to transform the educational process into a home occupation in compliance with individual level and pace. Electronic media committed to provide specialized courses organized by corporations and communities for individual listeners and audience will provide opportunities for each group with special needs or local needs and to develop a unique talent. The nature and balance in the work of teachers will change to virtual creativity and teamwork, whose priority is structuring and modeling curricula and processes. Secondly - providing access to all sorts of sources - the world's libraries, databases and virtual laboratories and the third - interaction with learners. [Chobanov, Kirova] "Interactive learning in real time will revolutionize education." [Celente, 
"Mircea cel Batran" Naval Academy Scientific Bulletin, Volume XXI - 2017 - Issue 2 The journal is indexed in: PROQUEST / DOAJ / Crossref / EBSCOhost/ INDEX COPERNICUS/ OAJI / DRJI I JOURNAL INDEX / I2OR / SCIENCE LIBRARY INDEX / Google Scholar / Academic Keys / ROAD Open Access I

Bibliography: Academic Resources / Scientific Indexing Services / SCIPIOI JIFACTOR

[1] Celente, Gerald. Trends 2000, p. 315, 1997.

[2] Chobanov, G., L. Genov, Literary Network / LiterNet and Bulgarian literature, culture and education in the digital world. // E-journal LiterNet, 17.06.1999,http://liternet.bg/publish/gchobanov/liternet.htm> (28.12.2005). Also: Literary Newspaper, 12.-18.05.1999, № 18. Also: Bulgarian Language and Literature, 1999, № 4, 5762 (version).

[3] Cole, Michael Cultural Psychology: A Once and Future Discipline. President and Fellows of Harvard College, p. 451, 1996.

[4] Doncheva, J. A Comparative Analysis on the topic of ethnicities developed by various teams of authors of curriculum systems of pre-school education in the Republic of Bulgaria. IN: 16th Conference of the Balkan Society for Pedagogy and Education "The Image of the "Other"/the Neighbour In the Educational Systems of the Balkan Countries", University of Macedonia, Thessaloniki, Greece, 2013, ISBN 978-960-8396-94-4.

[5] Ivanov, J. M., Yoga and psycho: Road to cosmic consciousness. Moscow, p. 287, LTD, 1991.

[6] Janakiev M. Project Neogea http://www.language-change.ibl.bas.bg> (23.10.2000; 28.12.2016).

[7] Kirova, L. learning the principles of postmodern learning. E-magazine LiterNet, 24.07.2001, № 7.

[8] Labov, William. The Logic of Non-standart English. // Language and Poverty. Ed. F. Williams. Chicago: Markham, 1972.

[9] Petrova, E., Motivation - modern aspects and trends, Proceedings of the jubilee scientific and practical conference "Bulgaria in the beginning of XXI century - economic, legal and social transformation", Veliko Tarnovo, ed. Faber, pp. 128-131, 2002.

[10] Sharlanova, V. Competence of pedagogical specialists to work with gifted and talented children and students at the beginning of the XXI century. // Education Forum. Br. 2, p. 28-34, 2014.

[11] Tsankova M. System methodological training in natural science student's future teachers in elementary school. // Coll. Provide and evaluate the quality of education. "Veda Slovena-JG' Sofia, p.243-248, 2005.

[12] Turkle, Sherry. Life on the Screen: Identity of the Age of the Internet. London, Phoenix, 1997. (Originally published: Simon \& Schuster, New York, 1995.

[13] Vinarova J., P.Mihova, Cultural genesis of specialized medical terminology of BMU`s BG section in 1966-1987 period, Archives of Balkan Medical Union, Celsius Pub. House., ISSN: 1584-9244, VOL. 51, JUNE 2016,http://www.balkanmedicalunion.com/en/article/cultural-genesis-of-medical-terminology-in-thebulgarian-section-of-bmu-during-the-1964-1987-period. 